\title{
Small Intestine Gastrointestinal Stromal Tumour-A Case Report
}

\author{
Sivaram Sridharan*, Ruban Kumar, K. B. Dinesh, B. S. Sundaravadanan, \\ Vignaradj Kirouchenaradj, S. Balamurali
}

Department of General Surgery, Saveetha Medical College Hospital, Kancheepuram, India

Email: *shiv316@gmail.com

How to cite this paper: Sridharan, S., Kumar, R., Dinesh, K.B., Sundaravadanan, B.S., Kirouchenaradj, V. and Balamurali, S. (2020) Small Intestine Gastrointestinal Stromal Tumour-A Case Report. Case Reports in Clinical Medicine, 9, 7-14.

https://doi.org/10.4236/crcm.2020.91002

Received: October 21, 2019

Accepted: December 27, 2019

Published: December 30, 2019

Copyright $\odot 2020$ by author(s) and Scientific Research Publishing Inc. This work is licensed under the Creative Commons Attribution International License (CC BY 4.0).

http://creativecommons.org/licenses/by/4.0/

\begin{abstract}
Gastrointestinal stromal tumours (GIST) are mesenchymal tumours that arise most commonly from the stomach. They are the $3^{\text {rd }}$ most common tumour diagnosed behind adenocarcinomas and lymphomas. The majority of these tumours are asymptomatic and incidentally diagnosed in UGI scopy or contrast enhanced CT abdomen and pelvis studies. Obstruction, ulceration, gastrointestinal (GI) haemorrhage and perforation warrants an urgent surgical intervention. GIST is medically managed by tyrosine kinase inhibitors and surgically by resection and anastomosis. This case report highlights the diagnosis and management of a 42-year-old gentleman who presented with vague right iliac fossa mass. Informed consent was obtained from the patient for publication of this case. This case was chosen to be reported because of the rare incidence of small intestine GIST in South India and the effectiveness of minimally invasive laparoscopic surgery in management.
\end{abstract}

\section{Keywords}

Small, Intestine, Gastrointestinal, Stromal, Tumour, GIST, Ileum, Case, Report

\section{Introduction}

GISTs are classified under stromal tumours. In India, it affects middle aged 40-year-old men more commonly than women [1] [2]. Kindblom et al. in 1998 concluded that the pluripotent mesenchymal cells finally differentiate into the interstitial cells of Cajal, which is the origin of GIST. These cells are found in the muscularis propria that initiates and coordinates GI motility. They are the "pacemaker cells" of the gastrointestinal tract [3]. The differentiation from stem cell to interstitial cells of Cajal is regulated by KIT kinase. The association between 
mutations in c-KIT proto-oncogene $(85 \%$ - 95\%) and GIST was described by Hirota and colleagues [4].

\section{Case Presentation}

A 42-year-old gentleman presented with complaints of vague right sided lower abdominal pain on and off for the past 6 months. He also complains of non-specific dyspepsia and abdominal distension. He has had multiple visits to the hospital and numerous consultations but to no avail. His general examination was unremarkable and per abdomen examination revealed tenderness in the right iliac fossa on deep palpation. Ultrasound of the abdomen and pelvis revealed heterogenous, peripheral enhancing lesion of $6.2 \times 5.5 \mathrm{~cm}$ in size that seems to be arising from the small bowel. With the suspicion of GIST, a contrast enhanced CT scan of the abdomen and pelvis (Figure 1) revealed a soft tissue mass lesion arising from the mid ileal loops that showed peripheral enhancement and central non enhancement post contrast administration.

Patient was pre-operatively fit for surgery. Laparoscopic removal of the GIST with resection and anastomosis of the small intestine was planned. Figure 2 shows a $6 \times 6 \mathrm{~cm}$ cystic lesion was adherent to the mesentry and was exophytic in nature. Figure 3 demonstrates the use of a Covidien $60 \mathrm{~mm}$ stapler to resect the specimen after adequate small bowel clearance $(5 \mathrm{~cm})$. Ileal anastomosis done using a Covidien $60 \mathrm{~mm}$ stapler (Figure 4). The specimen was retrieved though an upper midline laparotomy incision and sent for histopathological examination.

Gross histopathological examination revealed the tumour size of $6 \times 5.5 \times 5$ $\mathrm{cm}$ with negative margins (Figure 5). Microscopic studies revealed spindle cell type of GIST with 0 - 1 mitoses per 50 high power field. The pathological classification (TNM) of the tumour was $\mathrm{T}_{3} \mathrm{~N}_{\mathrm{x}}$.

Post operatively, he was started on clear liquids on POD 3, normal diet on

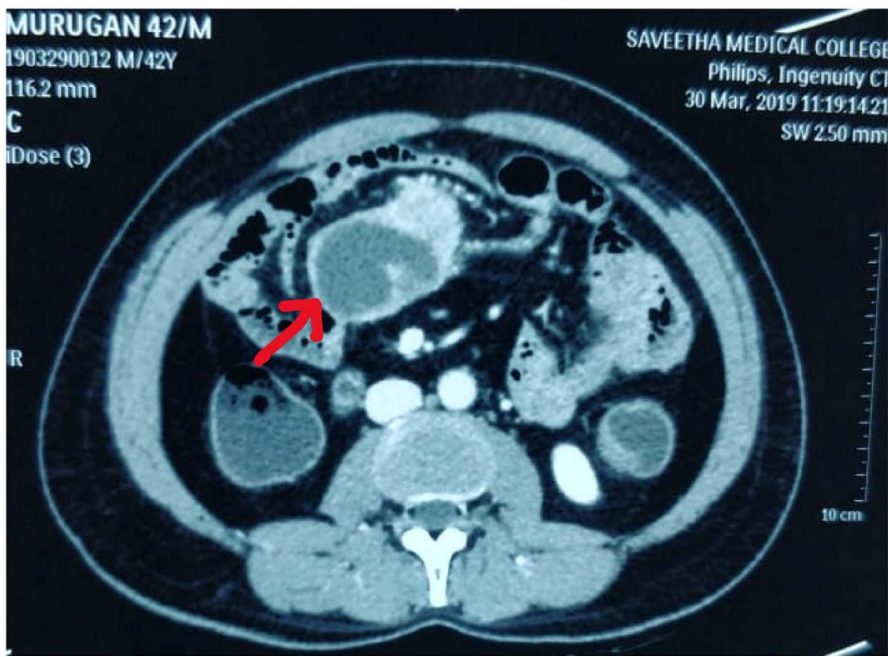

Figure 1. Shows the site of the small intestine GIST on contrast enhanced CT of the abdomen and pelvis (Red arrow). 


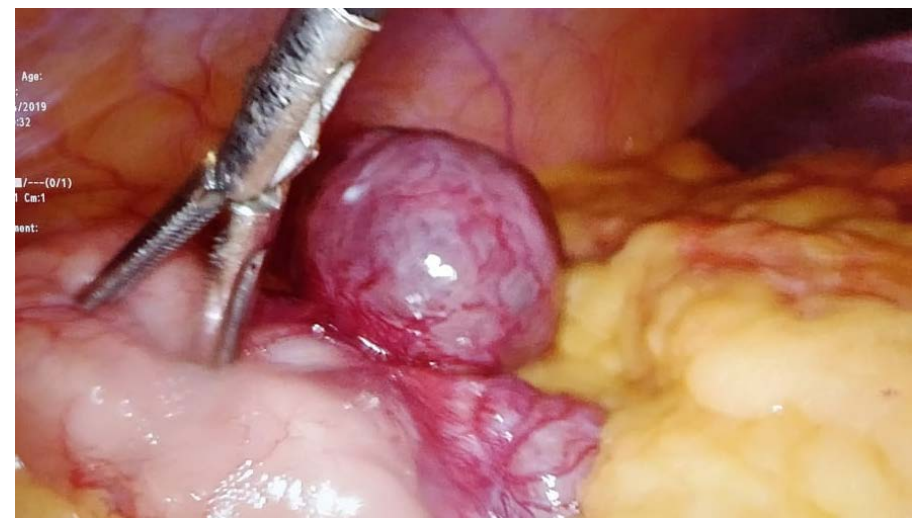

Figure 2. Shows the exophytic small intestine GIST (Intra-operative photo).

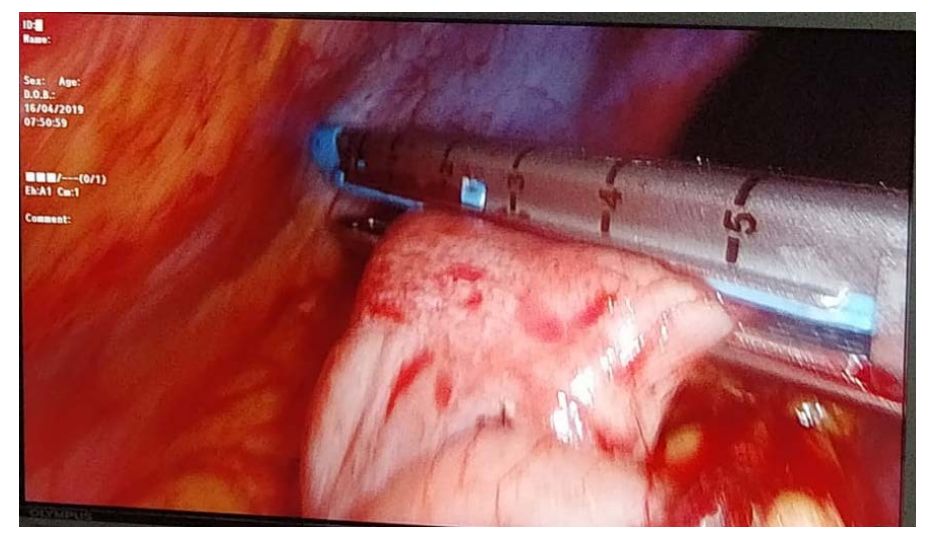

Figure 3. Shows the resection of the small intestine with a Covidien $60 \mathrm{~mm}$ stapler.

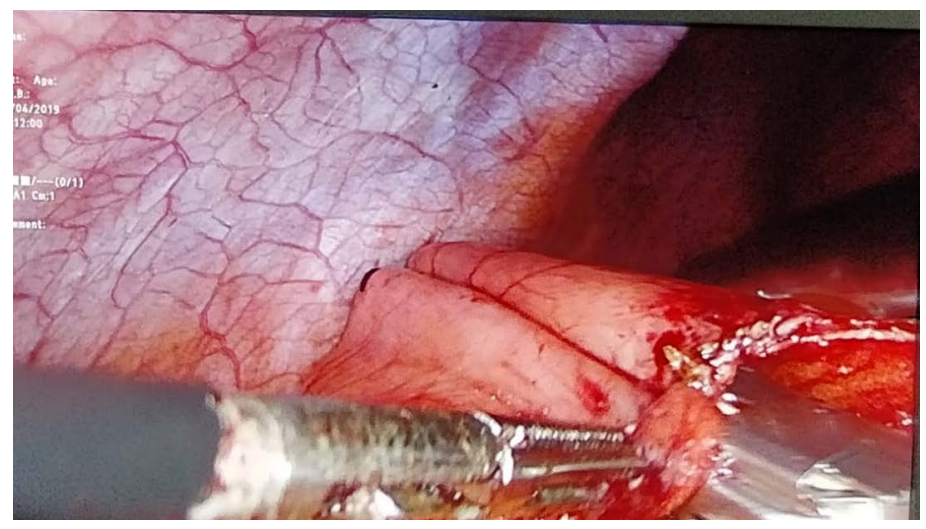

Figure 4. Shows the side to side anastomosis of small intestine with a Covidien $60 \mathrm{~mm}$ stapler.
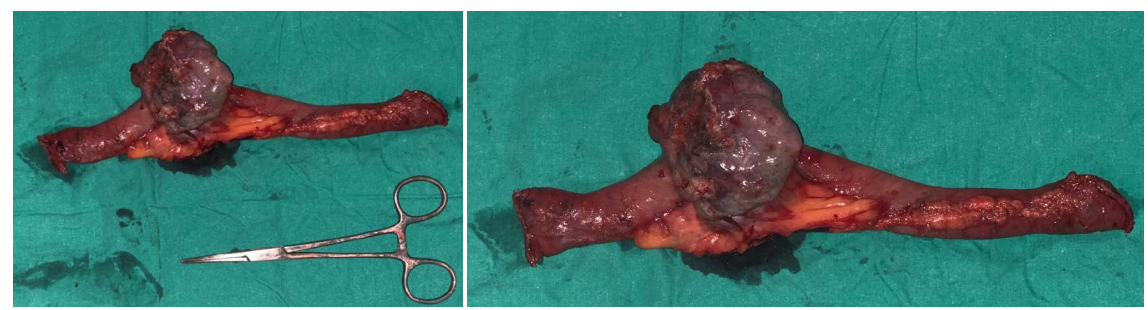

Figure 5. Shows the gross resected specimen. 
POD 5 and was referred to Medical Oncology for further management. The medical oncology team advised Tab. Imatinib $600 \mathrm{mg}$ for 6 months. Patient had serial contrast enhanced CT scans to monitor his response to the tyrosine kinase inhibitor. He is on regular follow-up and doing well. His last visit to the surgical out patients department was uneventful, his midline and port site scars healed and is leading his regular lifestyle.

\section{Discussion}

GISTs are either single or multiple with their size ranging from $>1 \mathrm{~cm}$ to a maximum of $40 \mathrm{~cm}$ in diameter [5]. They are commonly found in the body of the stomach (70\%) [6]. The jejunoileal site is the second most common site followed by rare presentations in the esophagus, colon, rectum and extra-GI sites [7] [8] [9]. Extraluminal GISTs are asymptomatic and can grow for an extended period and present as a large abdominal mass. Intraluminal GISTs cause complications like obstruction, mucosal ulceration, GI hemorrhage, perforation and peritonitis. If left untreated, they metastasise to the liver. Lymph node metastasis is rare.

At the genetic level, mutations involving c-KIT and PDGFRA are known to be involved in the pathogenesis of GIST. Patients with an exon 11 mutation results in a gain of function KIT mutation [10]. KIT is involved in the phosphorylation of several downstream proteins that results in mitogenic activity and protein transcription. Mutations in KIT sends proliferative signals to the nucleus that evades apoptosis and hence leading to tumorigenesis [11]. PDGRFA mutations are less common and are associated with gastric and epithelioid GISTS [12]. Exon 18 is most commonly involved [13].

GISTs are asymptomatic and are usually incidental findings during endoscopic, surgical procedures or radiological investigations [14]. A previously healthy individual with an abdominal mass gradually increasing in size can present with abdominal discomfort, anorexia, nausea, vomiting and weight loss [15]. An intraluminal growth can cause site specific obstruction (for example, gastric GIST presenting as gastric outlet obstruction) whereas an extraluminal growth can cause luminal compression due to the external pressure effect exerted by the enlarging mass. A palpable mass can be felt in the abdominal cavity and is detected in exophytic GISTs.

The most common complication is upper GI haemorrhage that presents as hematemesis or melena. The mass causes pressure necrosis and ulceration of the mucosal surface which results in haemorrhage due to the disrupted blood vessels. Perforation is associated with signs of peritonitis and shock [16] [17]. Kim MS et al. reported a rare case of intussusception due to a GIST [18].

While routine blood investigations and organ specific tumour markers are non specific in diagnosing GISTs, imaging and endoscopic studies are more specific. Plain chest and abdomen radiographs help in identifying those patients with an obstruction or perforation but are nonspecific to GISTs. Dualim DM et al. highlighted the use of a capsule endoscopy and double balloon enteroscopy in 
the diagnosis of a bleeding jejunal GIST [19]. Barium studies and enteroclysis provides information regarding the presence or absence of a mass but is not specific for GISTs. A filling defect that is sharply demarcated and elevated with the surrounding mucosa can be appreciated in barium studies [20].

Contrast enhanced computed tomographic (CT) abdomen and pelvis provides information regarding the size and location of the tumour and the surrounding structures [21]. Distant metastasis and infiltration of adjacent structures can also be identified on CT. Tumours between $5-10 \mathrm{~cm}$ present as irregular, heterogenous extraluminal or intraluminal masses that shows signs of biological aggression [22].

These tumours appear as spindle shaped cells with an increased cellularity. Factors like mitotic index, cellularity, nuclear-cytoplasmic ratio, amount of stroma and vascularity are taken into account for evaluating the prognosis of the disease.

GIST expresses CD117, which helps in differentiating GIST from other GI mesenchymal tumours [23] [24]. CD34 is expressed in 70\% of GISTs and indicate the probability of a lesion being malignant or not. Presence of CD44 indicates a better prognosis.

A multidisciplinary team, in a tertiary care centre, including a surgeon, radiologist, pathologist and medical oncologist is necessary for complete treatment of the disease. Complete resection of the tumour with negative margins is the surgical treatment of choice [21]. Small intestine GISTs are treated by a segmental resection and anastomosis. Lymphadenectomy is not routinely performed because of the lack of involvement. Unresectable tumours are treated with imatinib. Recently, laparoscopic approaches to deal with GISTs less than $5 \mathrm{~cm}$ in size have been successful. Piessen et al. reported that laparoscopic treatment of gastric GISTs was associated with significantly lower surgical and medical morbidity, and significantly better 5-year recurrence-free survival [25]. Faster recovery, shorter hospital stay and decreased analgesia are the advantages of laparoscopic surgery over open surgery. Tao et al. compared laparoscopic versus open surgery in the treatment of GIST and observed that operation time, time to first flatus and pre-operative hospital stay was shorter in the laparoscopic group. He concluded that laparoscopic intervention in experienced medical centers is best preferred for GISTs in unfavourable locations [26].

Newer minimally invasive surgical techniques that involve transrectal extraction of the resected GIST specimen have been highlighted by Wang X et al. After anal dilation, an incision was made in the upper rectum. A protective bag was inserted intra-abdominally into which the resected specimen was placed. The bag was pulled out making sure there is no capsular breach. The rectal stump was closed with a stapler. This method prevents an unwanted upper abdominal incision for retrieving the specimen [27].

Imatinib, a tyrosine kinase inhibitor, plays a major role in curing the disease post operatively. It can be administered pre-operatively to reduce the size of a 
large tumour and to achieve negative margins. A dose of $400 \mathrm{mg}$ daily, with the maximum dose of $800 \mathrm{mg} /$ day, is given for up to 2 years post-operatively [28] [29]. The response is monitored with the help of serial CT scans which reveals a decreased tumour density and tumour shrinkage [21].

\section{Conclusion}

Clinically impalpable lesions presenting with vague abdominal complaints must alert a surgeon to consider the possibility of GIST. Early identification, surgical intervention and post operative tyrosine kinase inhibitor therapy are the treatment of choice. Minimally invasive surgical modalities should be implemented in elective and emergency cases of GIST in tertiary care medical centres.

\section{Conflicts of Interest}

The authors declare no conflicts of interest regarding the publication of this paper.

\section{References}

[1] Rajappa, S., Muppavarapu, K.M., Uppin, S. and Digumarti, R. (2007) Gastrointestinal Stromal Tumors: A Single Institution Experience of 50 Cases. Indian Journal of Gastroenterology, 26, 225-229.

[2] Lakshmi, V.A., Chacko, R.T. and Kurian, S. (2010) Gastrointestinal Stromal Tumors: A 7-Year Experience from a Tertiary Care Hospital. Indian Journal of Pathology \& Microbiology, 53, 628-633. https://doi.org/10.4103/0377-4929.72005

[3] Kindblom, L.G., Remotti, H.E., Aldenborg, F. and Meis-Kindblom, J.M. (1998) Gastrointestinal Pacemaker Cell Tumor (GIPACT): Gastrointestinal Stromal Tumors Show Phenotypic Characteristics of the Interstitial Cells of Cajal. The American Journal of Pathology, 152, 1259-1269.

[4] Hirota, S., Isozaki, K., Moriyama, Y., Hashimoto, K., Nishida, T., Ishiguro, S., Kawano, K., Hanada, M., Kurata, A., Takeda, M., Muhammad Tunio, G., Matsuzawa, Y., Kanakura, Y., Shinomura, Y. and Kitamura, Y. (1998) Gain-of-Function Mutations of c-kit in Human Gastrointestinal Stromal Tumors. Science, 279, 577-580. https://doi.org/10.1126/science.279.5350.577

[5] Miettinen, M. and Lasota, J. (2001) Gastrointestinal Stromal Tumors-Definition, Clinical, Histological, Immunohistochemical, and Molecular Genetic Features and Differential Diagnosis. Virchows Archiv, 438, 1-12. https://doi.org/10.1007/s004280000338

[6] Miettinen, M., El-Rifai, W., Sobin, L. and Lasota, J. (2002) Evaluation of Malignancy and Prognosis of Gastrointestinal Stromal Tumors: A Review. Human Pathology, 33, 478-483. https://doi.org/10.1053/hupa.2002.124123

[7] Miettinen, M., Sarlomo-Rikala, M. and Lasota, J. (1999) Gastrointestinal Stromal Tumors: Recent Advances in Understanding of Their Biology. Human Pathology, 30, 1213-1220. https://doi.org/10.1016/S0046-8177(99)90040-0

[8] Reith, J.D., Goldblum, J.R., Lyles, R.H., et al. (2000) (Soft Tissue) Stromal Tumors: An Analysis of 48 Cases with Emphasis on Histologic Predictors of Outcome. Modern Pathology, 13, 577. https://doi.org/10.1038/modpathol.3880099

[9] Dematteo, R.P., Ballman, K.V., Antonescu, C.R., Maki, R.G., Pisters, P.W., Demetri, 
G.D., Blackstein, M.E., Blanke, C.D., von Mehren, M., Brennan, M.F., Patel, S., McCarter, M.D., Polikoff, J.A., Tan, B.R. and Owzar, K. (2009) Adjuvant Imatinib Mesylate after Resection of Localised, Primary Gastrointestinal Stromal Tumour: A Randomised, Double-Blind, Placebo-Controlled Trial. The Lancet, 373, 1097-1104. https://doi.org/10.1016/S0140-6736(09)60500-6

[10] Corless, C.L., Barnett, C.M. and Heinrich, M.C. (2011) Gastrointestinal Stromal Tumours: Origin and Molecular Oncology. Nature Reviews Cancer, 11, 865-878. https://doi.org/10.1038/nrc3143

[11] Rubin, B.P., Singer, S., Tsao, C., Duensing, A., Lux, M.L., Ruiz, R., et al. (2001) KIT Activation Is a Ubiquitous Feature of Gastrointestinal Stromal Tumors. Cancer Research, 61, 8118-8121.

[12] Lasota, J. and Miettinen, M. (2008) Clinical Significance of Oncogenic KIT and PDGFRA Mutations in Gastrointestinal Stromal Tumours. Histopathology, 53, 245-266. https://doi.org/10.1111/j.1365-2559.2008.02977.x

[13] Cassier, P.A., Ducimetière, F., Lurkin, A., et al. (2010) A Prospective Epidemiological Study of New Incident GISTs during Two Consecutive Years in Rhône Alpes Region: Incidence and Molecular Distribution of GIST in a European Region. British Journal of Cancer, 103, 165-170. https://doi.org/10.1038/sj.bjc.6605743

[14] Nilsson, B., Bumming, P., Meis-Kindblom, J.M., et al. (2005) Gastrointestinal Stromal Tumors: The Incidence, Prevalence, Clinical Course, and Prognostication in the Preimatinib Mesylate Era-A Population-Based Study in Western Sweden. Cancer, 103, 821-829. https://doi.org/10.1002/cncr.20862

[15] Zhao, X. and Yue, C. (2012) Gastrointestinal Stromal Tumor. Journal of Gastrointestinal Oncology, 3, 189-208.

[16] Ueyama, T., Guo, K.J., Hashimoto, H., et al. (1992) A Clinicopathologic and Immunohistochemical Study of Gastrointestinal Stromal Tumors. Cancer, 69, 947-955. https://doi.org/10.1002/1097-0142(19920215)69:4<947::AID-CNCR2820690419>3.0 .CO;2-X

[17] Miettinen, M., Sarlomo-Rikala, M., Sobin, L.H., et al. (2000) Gastrointestinal Stromal Tumors and Leiomyosarcomas in the Colon: A Clinicopathologic, Immunohistochemical, and Molecular Genetic Study of 44 Cases. The American Journal of Surgical Pathology, 24, 1339-1352. https://doi.org/10.1097/00000478-200010000-00003

[18] Kim, M.S., Woo, I.T., Jo, Y.M., Lee, J.H. and Park, B.S. (2019) Life-Threatening Bleeding with Intussusception Due to Gastrointestinal Stromal Tumor: A Case Report. Surgical Case Reports, 5, 154. https://doi.org/10.1186/s40792-019-0703-9

[19] Dualim, D.M., Loo, G.H., Rajan, R., Nik Mahmood, N.R.K. and Jejunal, G.I.S.T. (2019) Hunting Down an Unusual Cause of Gastrointestinal Bleed Using Double Balloon Enteroscopy. A Case Report. International Journal of Surgery Case Reports, 60, 303-306. https://doi.org/10.1016/j.ijscr.2019.06.053

[20] Tzen, C.Y. and Mau, B.L. (2005) Analysis of CD117-Negative Gastrointestinal Stromal Tumors. World Journal of Gastroenterology, 11, 1052-1055.

https://doi.org/10.3748/wjg.v11.i7.1052

[21] Demetri, G.D., van Oosterom, A.T., Garrett, C.R., Blackstein, M.E., Shah, M.H., Verweij, J., et al. (2006) Efficacy and Safety of Sunitinib in Patients with Advanced Gastrointestinal Stromal Tumour after Failure of Imatinib: A Randomised Controlled Trial. The Lancet, 368, 1329-1338. https://doi.org/10.1016/S0140-6736(06)69446-4

[22] NCCN (2016) Clinical Practice Guidelines in Oncology. Soft Tissue Sarcoma: Ver- 
sion 2. National Comprehensive Cancer Network. http://www.nccn.org/professionals/physician gls/pdf/sarcoma.pdf

[23] Piessen, G., Lefèvre, J.H., Cabau, M., et al. (2015) Laparoscopic versus Open Surgery for Gastric Gastrointestinal Stromal Tumors: What Is the Impact on Postoperative Outcome and Oncologic Results? Annals of Surgery, 262, 831-840. https://doi.org/10.1097/SLA.0000000000001488

[24] Yamashita, F., Sasatomi, E., Kiyama, M., Fukumori, K., Yano, Y., Kato, O., et al. (2001) Radiographic Observation of a Case of Gastrointestinal Stromal Tumor in Stomach. The Kurume Medical Journal, 48, 233-236. https://doi.org/10.2739/kurumemedj.48.233

[25] Franquemont, D.W. (1995) Differentiation and Risk Assessment of Gastrointestinal Stromal Tumors. American Journal of Clinical Pathology, 103, 41-47. https://doi.org/10.1093/ajcp/103.1.41

[26] Tao, K.X., Wan, W.Z., Chen, J.H., et al. (2019) Comparison of Propensity Scores between Laparoscopic and Open Surgery for Gastrointestinal Stromal Tumors in Patients with Difficult Gastric Anatomy. Chinese Journal of Surgery, 57, 585-590. https://doi.org/10.1007/s11605-019-04318-6

[27] Wang, X., Wang, P., Su, H., Liang, J., Zhou, H. and Zhou, Z. (2019) Laparoscopic Resection of Intestinal Stromal Tumors with Transrectal Extract Specimen: A Case Report. Medicine (Baltimore), 98, e16377. https://doi.org/10.1097/MD.0000000000016377

[28] ESMO/European Sarcoma Network Working Group (2014) Gastrointestinal Stromal Tumours: ESMO Clinical Practice Guidelines for Diagnosis, Treatment and Follow-Up. Annals of Oncology, 25, iii21-6. https://doi.org/10.1093/annonc/mdu255

[29] Ghanem, N., Altehoefer, C., Furtwängler, A., Winterer, J., Schäfer, O., Springer, O., et al. (2003) Computed Tomography in Gastrointestinal Stromal Tumors. European Radiology, 13, 1669-1678. https://doi.org/10.1007/s00330-002-1803-6 